\title{
Influence of increased heart rate and aortic pressure on resting indices of functional coronary stenosis severity
}

\author{
Lorena Casadonte $^{1} \cdot$ Bart-Jan Verhoeff $^{2,3} \cdot$ Jan J. Piek $^{2} \cdot$ Ed VanBavel $^{1}$.

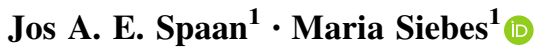

Received: 9 June 2017/ Accepted: 8 September 2017/Published online: 13 September 2017

(c) The Author(s) 2017. This article is an open access publication

\begin{abstract}
Baseline assessment of functional stenosis severity has been proposed as a practical alternative to hyperemic indices. However, intact autoregulation mechanisms may affect intracoronary hemodynamics. The aim of this study was to investigate the effect of changes in aortic pressure $(\mathrm{Pa})$ and heart rate $(\mathrm{HR})$ on baseline coronary hemodynamics and functional stenosis assessment. In 15 patients (55 $\pm 3 \%$ diameter stenosis) Pa, intracoronary pressure $(\mathrm{Pd})$ and flow velocity were obtained at control, and during atrial pacing at $120 \mathrm{bpm}$, increased $\mathrm{Pa}$ $(+30 \mathrm{mmHg})$ with intravenous phenylephrine (PE), and elevated $\mathrm{Pa}$ while pacing at sinus heart rate $(\mathrm{PE}+\mathrm{sHR})$. We derived rate pressure product $(\mathrm{RPP}=$ systolic $\mathrm{Pa} \times \mathrm{HR})$, baseline microvascular resistance $(\mathrm{BMR}=\mathrm{Pd} /$ velocity), and stenosis resistance $[\mathrm{BSR}=(\mathrm{Pa}-\mathrm{Pd}) / \mathrm{ve}$ locity] as well as whole-cycle $\mathrm{Pd} / \mathrm{Pa}$. Tachycardia $(120 \pm 1 \mathrm{bpm})$ raised RPP by $74 \%$ vs. control. Accordingly, BMR decreased by $27 \%(p<0.01)$ and velocity increased by $36 \%(p<0.05)$, while $\mathrm{Pd} / \mathrm{Pa}$ decreased by $0.05 \pm 0.02(p<0.05)$ and BSR remained similar to control. Raising Pa to $121 \pm 3 \mathrm{mmHg}$ (PE) with concomitant reflex bradycardia increased BMR by $26 \%$ $(p<0.001)$ at essentially unchanged RPP and velocity. Consequently, BSR and $\mathrm{Pd} / \mathrm{Pa}$ were only marginally
\end{abstract}

Maria Siebes

m.siebes@amc.uva.nl

1 Department of Biomedical Engineering and Physics, Academic Medical Center, University of Amsterdam, PO Box 22660, 1100 DD Amsterdam, The Netherlands

2 Department of Cardiology, Academic Medical Center, University of Amsterdam, Amsterdam, The Netherlands

3 Present Address: Department of Internal Medicine, St Jansdal Hospital, Harderwijk, The Netherlands affected. During PE + sHR, velocity increased by $21 \%$ $(p<0.01)$ attributable to a $46 \%$ higher $\operatorname{RPP}(p<0.001)$. However, BMR, BSR, and Pd/Pa remained statistically unaffected. Nonetheless, the interventions tended to increase functional stenosis severity, causing $\mathrm{Pd} / \mathrm{Pa}$ and BSR of borderline lesions to cross the diagnostic threshold. In conclusion, coronary microvascular adaptation to physiological conditions affecting metabolic demand at rest influences intracoronary hemodynamics, which may lead to altered basal stenosis indices used for clinical decision-making.

Keywords Coronary blood flow - Coronary artery stenosis - Metabolic adaptation - Baseline stenosis indices . Microvascular resistance

\section{Introduction}

Traditional indices for the functional assessment of coronary artery stenosis severity are derived from invasive intracoronary measurements obtained at maximal hyperemia. More recently, non-hyperemic indices obtained during contrast-induced reactive hyperemia $[16,27]$ or at resting coronary blood flow [23, 35, 37] have been introduced to facilitate functional stenosis assessment by obviating the need for vasodilator agents. Pressure-derived baseline indices include the distal coronary-to-aortic pressure ratio calculated over the entire cardiac cycle $(\mathrm{Pd} / \mathrm{Pa})$ $[15,23]$ or during a "wave-free" period in diastole, the instantaneous wave-free ratio (iFR) [1, 35]. In addition, basal stenosis resistance (BSR) has been proposed, defined as the ratio of the stenosis pressure gradient to resting flow velocity [37]. 
Although baseline indices have shown a strong correlation with the corresponding hyperemic values, the diagnostic accuracy suffers from a larger "gray zone" around the binary cut-off values for decision-making [15]. To improve diagnostic efficiency, while at the same time reducing the need for vasodilator drugs, hybrid strategies have been suggested, whereby hyperemia is only induced when measurements at resting flow fall within a certain gray zone [6, 7, 15, 30, 32].

Physiologically, coronary blood flow at rest is well regulated and adapted to metabolic demand [5, 14]. We hypothesized that variations in resting coronary blood flow in response to altered systemic pressure and myocardial oxygen consumption would affect resting indices of coronary stenosis severity. Accordingly, the aim of the present study was to investigate the influence of changes in heart rate and systemic pressure on physiological indices of stenosis severity, $\mathrm{Pd} / \mathrm{Pa}$ and $\mathrm{BSR}$, obtained in the presence of functional flow control mechanisms.

\section{Methods}

\section{Patient characteristics}

This is a single-center, retrospective study, which enrolled patients with stable coronary artery disease and a single de novo lesion in a coronary vessel scheduled for elective percutaneous coronary intervention. Clinical exclusion criteria were diffuse or three-vessel disease, ejection fraction below $30 \%$, recent myocardial infarction, serious valve abnormalities, prior cardiac surgery, hypertrophic cardiomyopathy, cardiac arrhythmia, abnormal clotting profiles, or severe renal failure.

\section{Cardiac catheterization and hemodynamic measurements}

All anti-anginal medication was continued. A $5 \mathrm{~F}$ - or $6 \mathrm{~F}$ guiding catheter was introduced via standard femoral approach for cardiac catheterization. Intracoronary nitroglycerin $(0.1 \mathrm{mg})$ was administered prior to diagnostic angiography and repeated if the procedure lasted more than 30 min. Distal pressure (Pd) and Doppler flow velocity were simultaneously measured downstream of the stenosis (ComboWire, Volcano Corp., Rancho Cordova, CA, USA). The pressure transducer was normalized to aortic pressure at the ostium prior to obtaining distal measurements, and care was taken to optimize the quality of the flow velocity signal. Potential pressure offsets were checked at the ostium at the end of the procedure. A $6 \mathrm{~F}$ bipolar pacemaker lead was placed into the right atrium. All signals were digitally recorded together with the ECG on a personal computer after 12-bit A/D conversion at $120 \mathrm{~Hz}$, as previously described [36].

\section{Experimental protocol}

Intracoronary hemodynamic signals were collected during a stable period at baseline (control) and after 2 min of atrial pacing at $120 \mathrm{bpm}(\mathrm{Pac})$. After return to baseline, $\mathrm{Pa}$ was elevated by slow intravenous infusion of phenylephrine (PE) at an initial rate of $12 \mathrm{mg} / \mathrm{min}$, adjusted upwards over a period of several minutes to reach a target increase in mean arterial pressure of $30 \mathrm{mmHg}$. Measurements at elevated pressure were repeated while pacing at sinus heart rate $(\mathrm{PE}+\mathrm{sHR})$ to counteract the reflex bradycardia during phenylephrine infusion.

\section{Data analysis}

Angiograms were quantitatively analyzed to yield study vessel dimensions and stenosis diameter reduction (QCACMS 5.2, Medis Medical Imaging Systems, Leiden, Netherlands). For each protocol step, we estimated oxygen consumption by the rate pressure product (RPP) as the product of peak systolic $\mathrm{Pa}$ and HR. Cycle-averaged values were obtained for all hemodynamic variables based on ECG R-peaks. We corrected for pressure drift by means of the zero-flow intercept extrapolated from the stenosis pressure drop-velocity relationship at the time of stenosis assessment, as done previously [27, 37]. Diastolic values of pressure and velocity measurements were determined as the average from the aortic pressure dicrotic notch to the ECG R-peak. Whole-cycle and diastolic $\mathrm{Pd} / \mathrm{Pa}$ were derived as pressure-only indices of stenosis severity. We determined BSR as the whole-cycle ratio of the stenosis pressure gradient $(\Delta P)$ to flow velocity and baseline microvascular resistance (BMR) as the ratio of $\mathrm{Pd}$ to flow velocity. Results represent the mean value over eight consecutive cycles.

\section{Statistical analysis}

Continuous data are expressed as mean \pm SEM. Normal distribution was checked with Shapiro-Wilk statistics. Effects of medication or risk factors on intrinsic resting flow velocity were assessed by multinomial logistic regression. Continuous variables at the patient level were compared between protocol steps using repeated measures analysis of variance followed by Tukey post hoc contrast analysis. Associations between variables at control and after hemodynamic provocation were assessed by linear regression analysis. A linear mixed-effects model with intervention as repeated effect at three levels was used to examine associations across all imposed interventions. 
Linear regression analysis with the models $(\mathrm{Pd} / \mathrm{Pa})_{\text {intervention }}$ $=A \times(\mathrm{Pd} / \mathrm{Pa})_{\text {control }}+(1-A)$ and $(\mathrm{BSR})_{\text {intervention }}=B$ $\times(\mathrm{BSR})$ control was performed to investigate the effect of functional stenosis severity on the change during the interventions from respective control values. These models satisfy the condition of $\mathrm{Pd} / \mathrm{Pa}=1$ and $\mathrm{BSR}=0$ in case of no stenosis. The respective ischemic thresholds for $\mathrm{Pd} / \mathrm{Pa} \leq 0.92$ [15] and BSR $>0.66 \mathrm{mmHg} \mathrm{cm}^{-1} \mathrm{~s}$ [37] were used for diagnostic classification. Statistical tests were performed using SPSS vs. 20 (IBM, Armonk, NY, USA). Two-tailed values of $p<0.05$ were considered statistically significant.

\section{Results}

\section{Patient characteristics}

Nineteen patients participated in this study. No patient experienced adverse clinical events or ischemic episodes during execution of the protocol. In three patients, it was not possible to perform the last step of the protocol due to patient discomfort related to the duration of the procedures. One patient was excluded from the analysis due to suboptimal flow signal quality. Therefore, the study population consisted of 15 patients with a stenosis of intermediate severity $(32-74 \%$ diameter reduction, reference diameter $3.06 \pm 0.18 \mathrm{~mm}$ ), predominantly located in the left anterior descending artery. Patient demographics and angiographic findings are summarized in Table 1.

Table 1 Demographics and stenosis characteristics $(n=15)$

\begin{tabular}{ll}
\hline Age (years) & $57 \pm 2$ \\
Male sex & $13(87)$ \\
Diameter reduction (\%) & $55 \pm 3$ \\
Study vessel LAD/LCX/RCA & $12 / 2 / 1(80 / 13 / 7)$ \\
Prior myocardial infarction & $2(13)$ \\
Coronary risk factors & \\
Hypertension & $6(40)$ \\
Smoking & $6(40)$ \\
Hypercholesterolemia & $8(53)$ \\
Diabetes & $0(0)$ \\
Medication & \\
ACE inhibitors & $3(20)$ \\
Aspirin & $14(93)$ \\
$\beta-B l o c k e r s$ & $10(67)$ \\
Calcium antagonist & $8(53)$ \\
Nitrates & $4(27)$ \\
\hline
\end{tabular}

Values are expressed as mean \pm SEM or $n(\%)$

$A C E$ angiotensin-converting enzyme, $L A D$ left anterior descending artery, $L C X$ left circumflex artery, $R C A$ right coronary artery

\section{Induced changes in systemic and coronary hemodynamics}

Hemodynamic variables and derived indices for all protocol steps are summarized in Table 2.

At control, $\mathrm{Pa}$ ranged from 79 to $121 \mathrm{mmHg}, \mathrm{Pd}$ from 73 to $114 \mathrm{mmHg}$, and heart rate from 52 to $94 \mathrm{bpm}$. Resting flow velocity ranged from 7.7 to $23.4 \mathrm{~cm} / \mathrm{s}$, with no difference due to medication or risk factors. In addition, BMR varied by a factor of three, ranging from 3.4 to $11.7 \mathrm{mmHg} \mathrm{cm}^{-1} \mathrm{~s}$, and was strongly inversely related to flow velocity $(r=-0.85, p<0.001)$. BMR or resting velocity had no significant relationship with stenosis diameter reduction (Fig. 1). Of note, the average heart rate for velocity data above the regression line was $78 \pm 5$ compared with $63 \pm 2 \mathrm{bpm}$ for those below, and vice versa for $\mathrm{BMR}(p<0.01)$. Both resting flow velocity $(r=0.58, p<0.05)$ and $\mathrm{BMR}(r=-0.52, p<0.05)$ were significantly associated with heart rate at control (Fig. 2).

Rapid atrial pacing increased heart rate by $52 \pm 3 \mathrm{bpm}$ (76\%) and raised $\mathrm{Pa}$ by $9 \pm 2 \mathrm{mmHg}$ (9\%) (both $p<0.001)$, while $\mathrm{Pd}$ remained essentially unchanged $(p=0.15)$. Resting coronary flow velocity increased by $5 \pm 1 \mathrm{~cm} / \mathrm{s}(36 \%, p<0.01)$ and $\Delta P$ by $6 \pm 2 \mathrm{mmHg}$ (67\%, $\quad p<0.01)$. BMR decreased by $1.9 \pm 0.4 \mathrm{mmHg} \mathrm{cm}^{-1} \mathrm{~s}(-27 \%, p<0.01)$.

Phenylephrine infusion elevated $\mathrm{Pa}$ by $25 \pm 2 \mathrm{mmHg}$ $(26 \%)$ vs. control $(p<0.001)$ with a concomitant reflex decrease in HR by $16 \pm 1 \mathrm{bpm}(-24 \%, p<0.001)$. Coronary flow velocity and $\Delta P$ remained equivalent to control ( $p=0.43$ and $p=0.24$, respectively), while $\mathrm{Pd}$ increased by $23 \pm 3 \mathrm{mmHg}(26 \%, p<0.001)$ and BMR by $2.0 \pm 0.7 \mathrm{mmHg} \mathrm{cm}^{-1} \mathrm{~s}(28 \%, p<0.05)$.

Additional pacing at sinus heart rate further increased $\mathrm{Pa}$ to $38 \pm 3 \mathrm{mmHg}(40 \%)$ above control $(p<0.001)$. Distal flow velocity increased by $3 \pm 1 \mathrm{~cm} / \mathrm{s}(21 \%)$ and $\mathrm{Pd}$ by $33 \pm 4 \mathrm{mmHg}(+38 \%)$ vs. control (both $p<0.01)$, with a $5 \pm 2 \mathrm{mmHg}(56 \%)$ increase in $\Delta P(p<0.01)$. BMR decreased by $1.5 \pm 0.2 \mathrm{mmHg} \mathrm{cm}^{-1} \mathrm{~s}(-17 \%, p<0.001)$ vs. PE, to a similar level as in control ( $p=0.43)$.

As shown in Fig. 3, RPP tended to increase slightly above control levels during PE $(6 \%, p=0.07)$, whereas Pac and PE + sHR substantially raised RPP by 74 and $46 \%$, respectively (both $p<0.001$ ).

Figure 4 illustrates that changes in RPP from control were strongly associated with changes in HR across all interventions $(p<0.001)$. Accordingly, changes in flow velocity and BMR (Fig. 5) during the hemodynamic provocations were strongly related to changes in RPP (both $p<0.001)$.

Overall, diastolic and whole-cycle results (Table 2) changed in the same direction in response to altered 


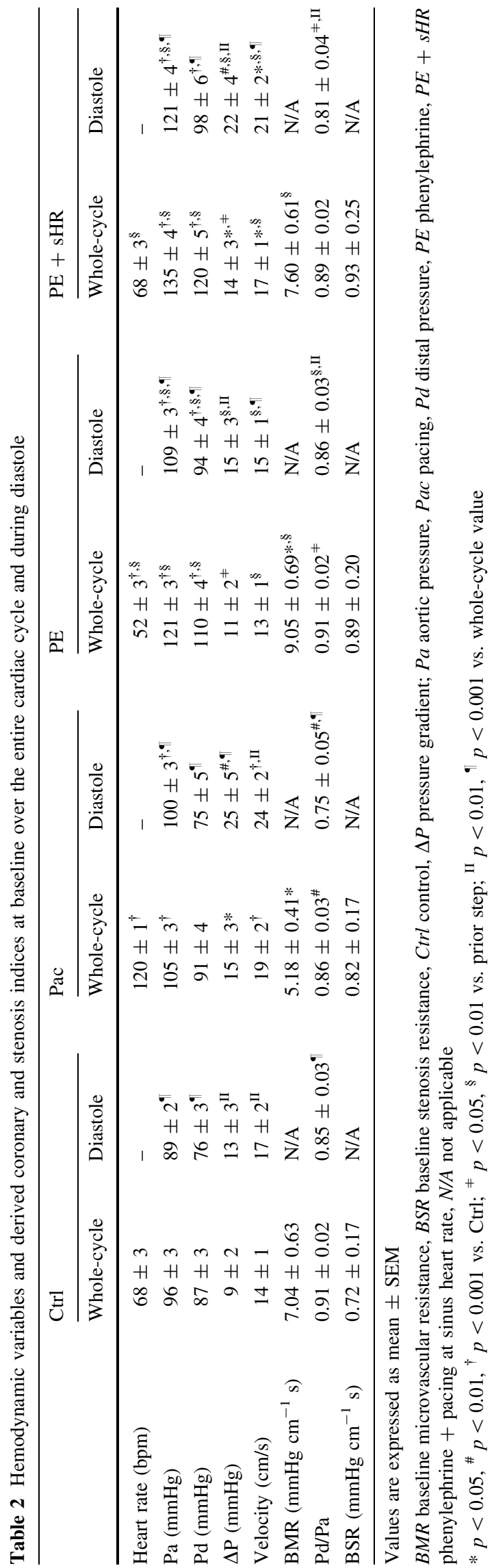

conditions. Although diastolic velocity and $\Delta P$ were higher compared with whole-cycle averages, non-significant changes vs. control observed for whole-cycle averages remained non-significant also for diastolic averages.

\section{Induced changes in basal functional indices}

On average, the intra-patient whole-cycle decrease in $\mathrm{Pd} / \mathrm{Pa}$ from control during pacing was $0.05 \pm 0.02(p<0.01)$, while no significant change was observed during $\mathrm{PE}$ $(p=0.97)$ or $\mathrm{PE}+\mathrm{sHR}(p=0.21)$. Diastolic $\mathrm{Pd} / \mathrm{Pa}$ was lower for each condition compared with whole-cycle $\mathrm{Pd} / \mathrm{Pa}$ $(p<0.001$ for Ctrl and Pac, $p<0.01$ for PE and $\mathrm{PE}+\mathrm{sHR}$ ), and showed the same behavior for changes from control. Although BSR increased from control by $0.10 \pm 0.07,0.17 \pm 0.12$, and $0.22 \pm 0.14 \mathrm{mmHg} \mathrm{cm}^{-1} \mathrm{~s}$ during Pac, PE, and PE + sHR, respectively, statistical significance was not reached (Table 2).

Changes from control in both BSR (Fig. 6a) and velocity (Fig. 6b) during the interventions were negatively correlated with changes in $\mathrm{Pd} / \mathrm{Pa}$. To put the observed variations in baseline indices resulting from altered heart rate and aortic pressure into diagnostic perspective, we normalized these to the respective non-ischemic decision margin for BSR $\left(0.66 \mathrm{mmHg} \mathrm{cm}^{-1} \mathrm{~s}\right)$ and $\mathrm{Pd} / \mathrm{Pa}$ $(0.08=1-0.92)$. The average normalized change during Pac, PE, and PE + sHR was, respectively, 15, 26, and 33\% of the non-ischemic range for BSR, and $-58,1$ and $-19 \%$ for $\mathrm{Pd} / \mathrm{Pa}$.

Figure 7 shows the relation between pairs of values for $\mathrm{Pd} / \mathrm{Pa}$ and BSR obtained before and after the hemodynamic interventions. Model-based regression analysis (Fig. 7a) demonstrated that especially tachycardia had a progressively lowering effect on $\mathrm{Pd} / \mathrm{Pa}$ with increasing physiological stenosis severity at control $(r=0.81, p<0.01)$. Similar results were obtained for diastolic $\mathrm{Pd} / \mathrm{Pa}$. In contrast, despite a worsening trend, changes in BSR (Fig. 7b) were much less related to its value at control.

Nonetheless, several borderline lesions switched diagnostic classification during hemodynamic provocation, with an overall worsening tendency. $\mathrm{Pd} / \mathrm{Pa}$ became functionally significant during pacing tachycardia for four lesions (27\%), and not significant for one (7\%), while 2 lesions each (13\%) crossed the $\mathrm{Pd} / \mathrm{Pa}$ threshold in opposite directions both during PE and PE + sHR (Fig. 7a). Each of the hemodynamic provocations caused the BSR of three lesions (20\%) to become functionally significant (Fig. 7b). Two patients in which $\mathrm{Pd} / \mathrm{Pa}$ became diagnostically significant during pacing were the same as those in which BSR became significant.

Changes in diagnostic classification for diastolic $\mathrm{Pd} / \mathrm{Pa}$ could not be assessed, since there is no established threshold for diastolic $\mathrm{Pd} / \mathrm{Pa}$ as we calculated it. 


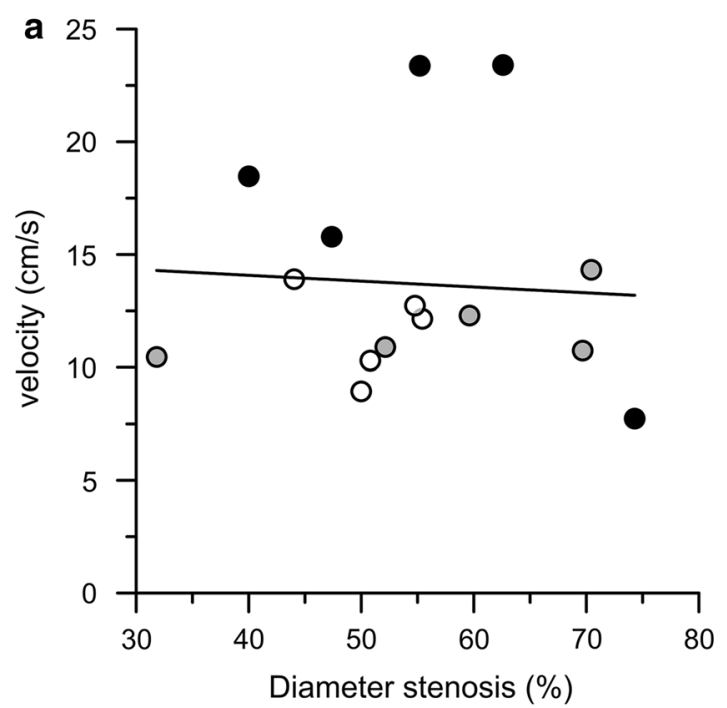

Fig. 1 Resting blood flow velocity and baseline microvascular resistance (BMR) at control vs. anatomical stenosis severity. Flow velocity (a) or BMR (b) was not related to diameter stenosis.

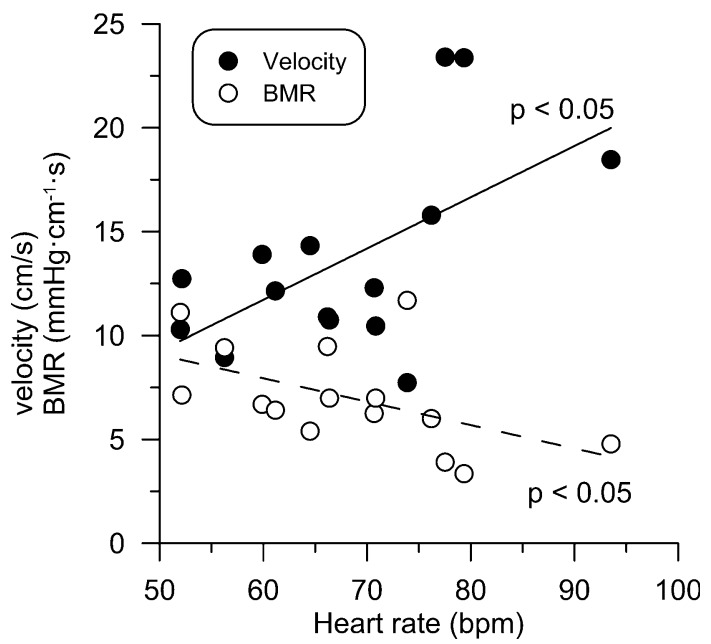

Fig. 2 Dependence of resting flow velocity and baseline microvascular resistance (BMR) on heart rate at control. Coronary flow velocity increased significantly with resting $\mathrm{HR}$, whereas BMR decreased

\section{Discussion}

In this study, we altered aortic pressure and heart rate at resting conditions to evaluate the dependence of baseline indices of functional stenosis severity on hemodynamic provocations in the presence of a functional autoregulation. The main findings are: (1) resting flow velocity and BMR at control were related to heart rate, rather than anatomical stenosis severity. (2) BMR and, consequently, velocity adapted as a physiological response to prevailing myocardial metabolic demand. (3) Basal indices of

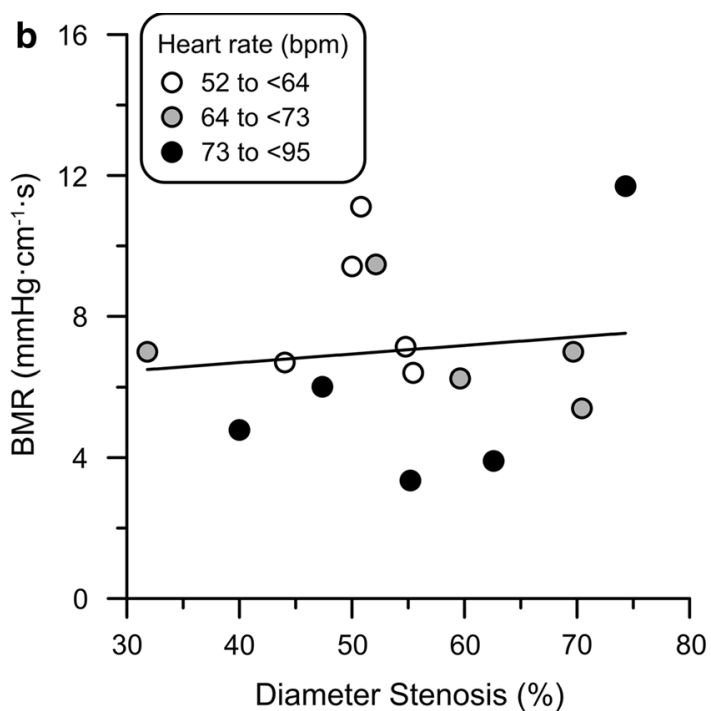

However, the average heart rate differed significantly for data points above the regression line compared with those below $(p<0.01)$

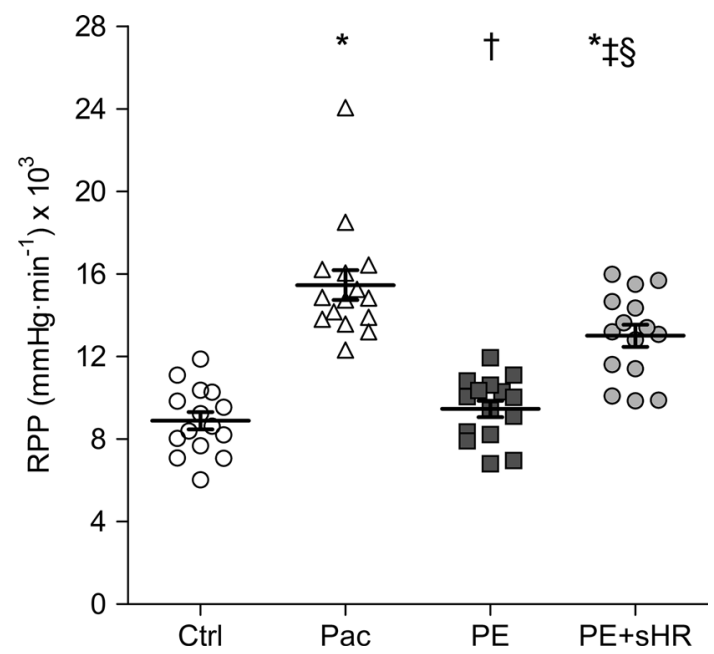

Fig. 3 Rate pressure product (RPP) during different stages of the protocol. RPP did not change from control (Ctrl) during elevated aortic pressure (PE) with reflex bradycardia, but increased by 74 and $46 \%$ during pacing $(\mathrm{Pac})$ and elevated $\mathrm{Pa}$ at sinus heart rate $(\mathrm{PE}+\mathrm{sHR})$, respectively. $* p<0.001$ compared with control, ${ }^{\dagger} p<0.001$ and ${ }^{\star} p<0.01$ compared with Pac, ${ }^{\$} p<0.001$ compared with $\mathrm{PE}$

stenosis severity were differentially affected depending on concurrent changes in coronary flow velocity and distal pressure. Tachycardia had the largest effect, especially on $\mathrm{Pd} / \mathrm{Pa}$. (4) For about $20 \%$ of borderline lesions, BSR and $\mathrm{Pd} / \mathrm{Pa}$ crossed their respective diagnostic threshold to a physiologically significant classification during the interventions. 


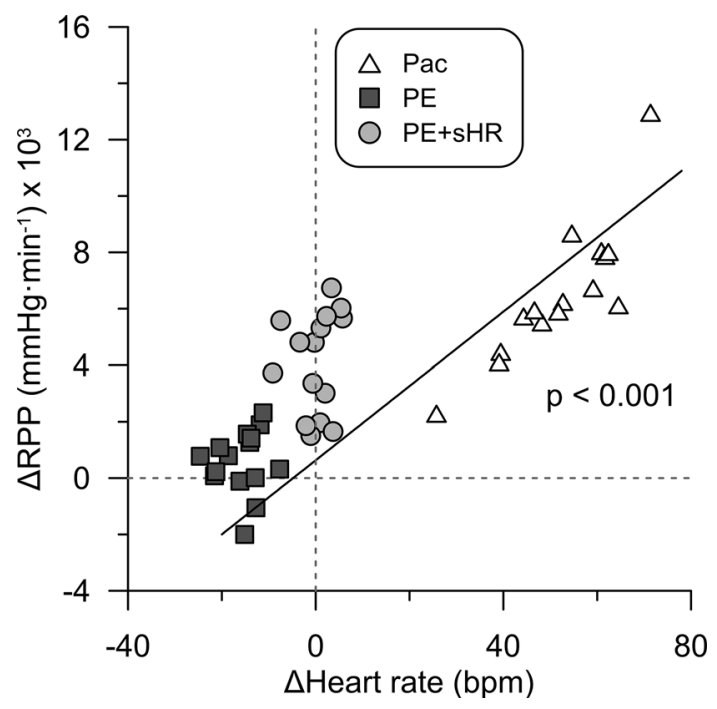

Fig. 4 Effect of changes in heart rate on myocardial oxygen consumption. Changes in heart rate from control were positively associated with changes in rate pressure product (RPP). Pac pacing, $P E$ phenylephrine, $P E+s H R$ PE while pacing at sinus heart rate

\section{Effect of Pa and HR on basal coronary hemodynamics}

The functional assessment of stenosis severity at baseline is an attractive option from a procedural point of view, since it does not require pharmacological vasodilation. Important physiological principles concerning resting indices are the recruitment of coronary dilatory capacity to adapt coronary blood flow to metabolic demand and autoregulatory compensation for reduced post-stenotic pressure [5, 14]. Coronary autoregulation is the result of a complex interaction

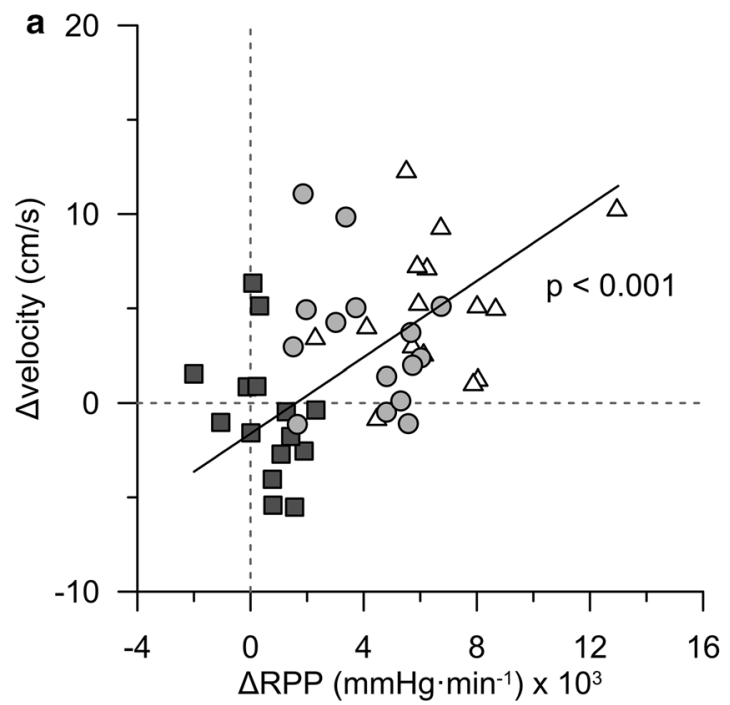

Fig. 5 Effect of changes in oxygen consumption on changes in coronary flow velocity and baseline microvascular resistance (BMR). Changes in rate pressure product (RPP) from control across all of various mechanisms active at different levels of resistance vessels in the coronary tree. All arteries with diameter $<400 \mu \mathrm{m}$ contribute to the control of blood flow and autoregulation. A change in metabolic state is coupled via several mechanisms to microvascular function (resistance) and multiple neuro-humoral factors modulate microvascular control (e.g. $\alpha$-agonist vasomotion and $\beta$-adrenergic increase in metabolic demand) $[5,12]$. In addition, pathological syndromes affect regulation of resistance vessels depending on their diameter $[9,10,29]$. Resting coronary blood flow per myocardial mass is mainly related to oxygen consumption, which in turn depends on major factors such as heart rate and cardiac workload [5, 14]. This may well introduce considerable variability according to the actual metabolic state of individual patients. Modulation of resting coronary flow has also been reported due to circadian variation in sympathetic activity or via sympathetic stimulation during catheterization procedures [8, 25]. However, such biological variability has not been taken into account when assessing resting indices of stenosis severity and their diagnostic accuracy.

A major justification for pressure-based resting indices derives from the presumption of constant resting flow velocity regardless of stenosis severity. Yet, such generalization of constant basal flow velocity in fact implies a similar statement on constant metabolic demand for all interrogated patients. The average resting flow velocity was recently reported to be constant across a wide spectrum of stratified stenosis severities [26], whereas the stated variation around the mean may well reflect effects of heart rate for individual patients, which unfortunately was not reported or considered in that study. Our pre-intervention

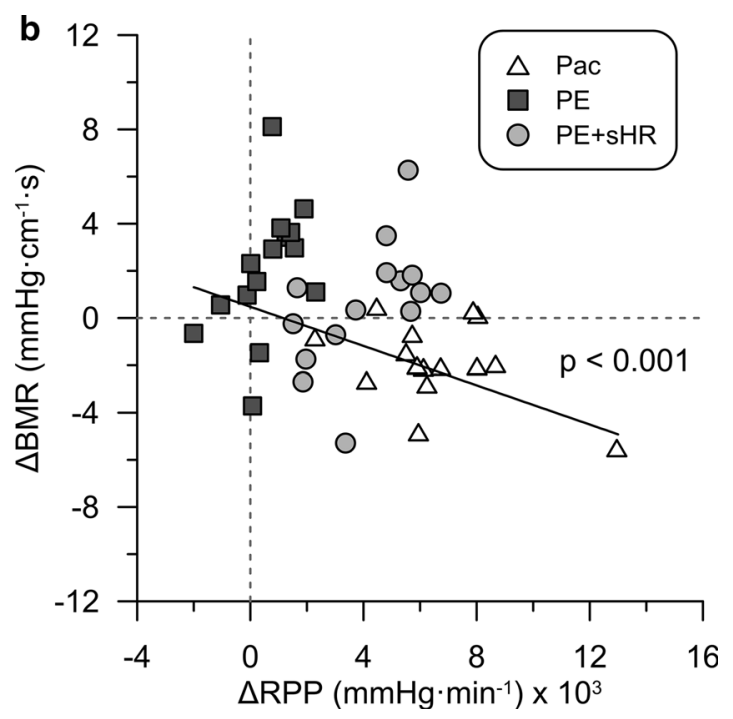

interventions were a positively associated with changes in coronary flow velocity and $\mathbf{b}$ inversely with changes in BMR 

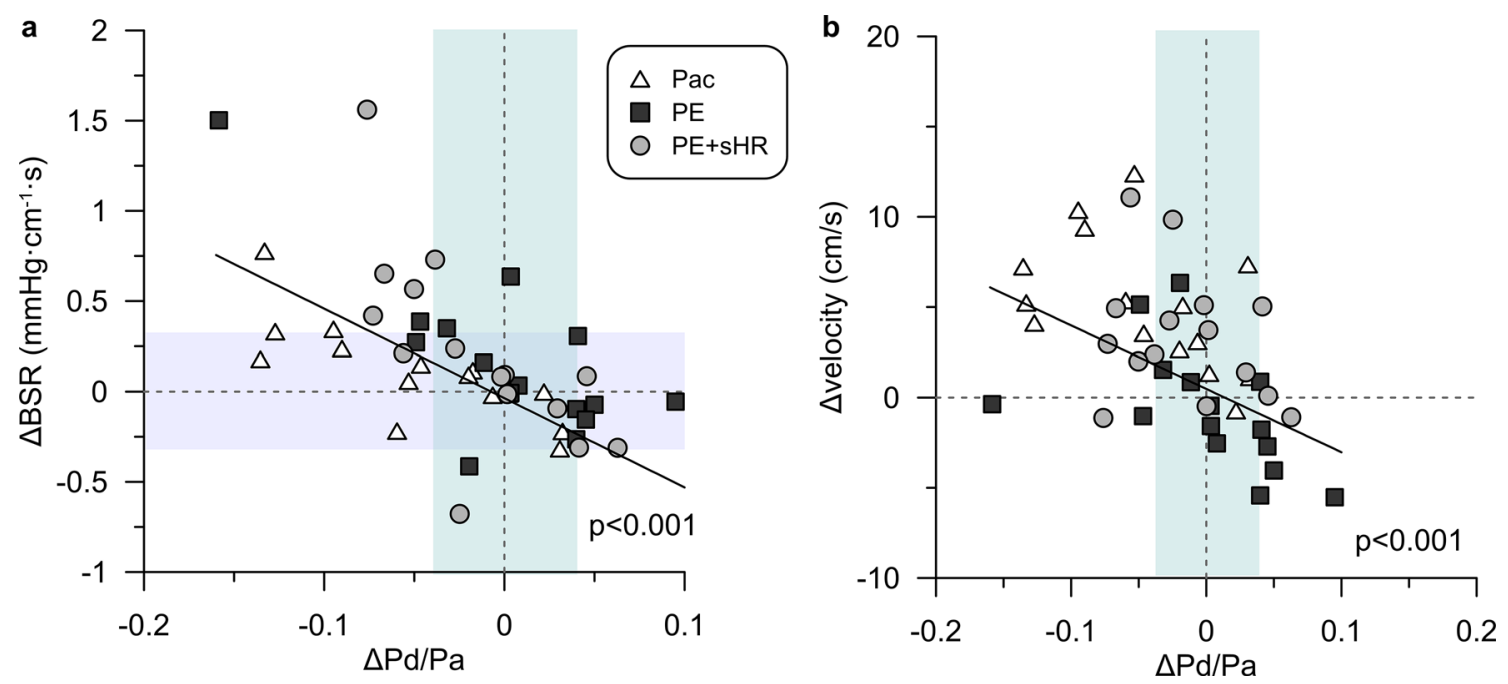

Fig. 6 Individual changes a in basal stenosis resistance (BSR) and $\mathbf{b}$ in baseline flow velocity vs. changes in whole-cycle $\mathrm{Pd} / \mathrm{Pa}$ induced by metabolic adaptation during the interventions. These changes exceeded the extent of the respective non-ischemic range for each

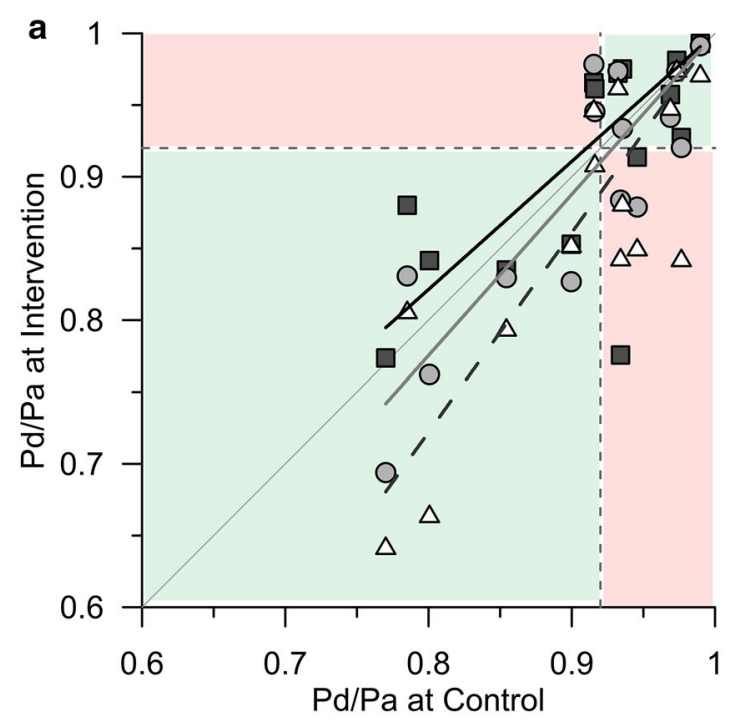

Fig. 7 Comparison of baseline stenosis indices during hemodynamic provocation vs. control. The respective diagnostic threshold is indicated by the dashed lines. a Model-based regressions highlight the progressively lowering effect of pacing on $\mathrm{Pd} / \mathrm{Pa}$ with increasing stenosis severity. Four lesions became functionally significant and one lost significance during pacing, while two lesions each crossed the threshold in opposite directions during the other interventions involving elevated aortic pressure. b BSR tended to increase during

findings show that baseline velocity was not constant across all stenosis severities, but varied with the intrinsic patient-specific heart rate at control. Significant relationships were found between coronary flow velocity and BMR, as well as between BMR or velocity and heart rate, hence contrasting with those earlier findings [26].

Imposing controlled metabolic stressors elicited individual responses resulting in additional variability. index, as indicated by shaded areas for reference purposes. A significant negative correlation to changes in $\mathrm{Pd} / \mathrm{Pa}$ across all interventions was found for both the change in BSR and change in flow velocity

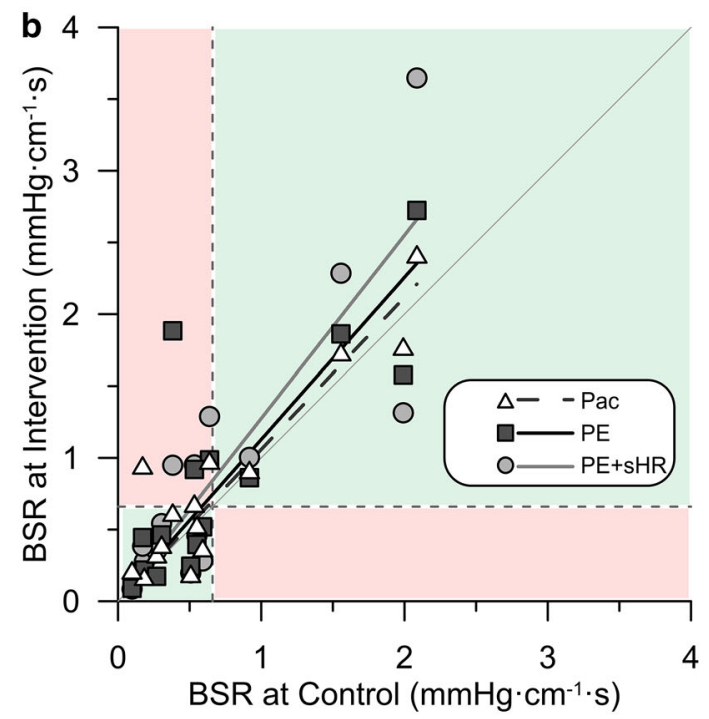

the hemodynamic provocations, with less dependence on functional lesion severity at control. Three lesions switched to a diagnostically significant BSR value during each intervention. Shaded areas indicate where the clinical classification agreed (green) or disagreed (red) between control and interventions. Pac pacing, $P E$ phenylephrine, $P E+s H R$ PE while pacing at sinus heart rate, $P d / P a$ distal-to-aortic pressure ratio, $B S R$ baseline stenosis resistance

Consistent with the previous findings in dogs [13, 19] and humans [24, 34, 39, 40], tachycardia increased oxygen consumption, inducing commensurate arteriolar vasodilation and a consequential increase in coronary flow velocity, while raising coronary distending pressure caused an increase of BMR as an autoregulatory response. Yet, one would expect some metabolic vasodilation because of increased cardiac afterload [2], which, however, was offset 
by reflex bradycardia, as reflected by the essentially unchanged RPP from control. The expected effect of increased cardiac afterload with elevated $\mathrm{Pa}$ became apparent when HR was restored to control levels during phenylephrine infusion. In fact, BMR was markedly reduced compared to PE alone, enabling an increase in coronary blood flow to meet the higher metabolic demand. These physiological responses to perturbations of coronary and systemic hemodynamics underlie potential changes in functional indices of stenosis severity assessed at baseline.

\section{Effects of changes in Pa and HR on basal stenosis indices and diagnostic classification}

We are not aware of other publications that reported changes in basal stenosis indices caused by altered metabolic demand in humans. In our study, the pressure-only index $\mathrm{Pd} / \mathrm{Pa}$ was more prone to be affected by alterations in resting coronary blood flow than BSR, which combines pressure and velocity measurements. During tachycardia, close to one-third of the lesions switched diagnostic classification compared to control according to the $\mathrm{Pd} / \mathrm{Pa}$ binary threshold. BSR tended to increase with pacing, similar to prior findings in dogs [13], but statistical significance was not achieved in our study.

We could not derive iFR, but would expect it to be similarly affected as whole-cycle or diastolic $\mathrm{Pd} / \mathrm{Pa}$ by changes in metabolic state at rest.

In general, baseline indices to identify the ischemic potential of coronary lesions suffer from a higher misclassification rate compared with established hyperemic indices $[11,15,17]$. This can partly be attributed to the low magnitude of intracoronary signals obtained at resting flow, which amplifies the relative effect of measurement errors due to pressure sensor drift (Pd), hydrostatic pressure offset $(\mathrm{Pa})$, or a lower signal-to-noise ratio (velocity) $[4,20,31,38]$ and has prompted some investigators to consider a decision-making strategy based on resting pressures a sub-optimal approach $[11,16]$. Since in general, the factors contributing to variability at baseline are relatively less potent at higher flow, contrast- or adenosine induced elevated flow is advisable and may also mitigate effects of altered metabolic state at the time of measurement.

\section{Study limitations}

We recognize that the small cohort of patients limits extension of our findings to a more general population. However, our results were consistent with physiological expectations and warrant further research on this topic in a larger group of patients.

The range and distribution of stenosis severities have been identified as a critical factor in terms of diagnostic accuracy for baseline indices [15]. Our re-classification rate following hemodynamic alterations should, therefore, be interpreted in this context and not be considered exemplary for a wider population. In addition, the heterogeneous distribution of stenosis severities in a small number of patients may also have adversely affected the significance of differences between the explored variables.

We gave phenylephrine intravenously to increase aortic pressure by increasing peripheral vasoconstriction. Phenylephrine may have stimulated $\alpha_{1}$-adrenergic receptors in epicardial coronary vessels [12]. In this respect, the absence of observable vasodilation during increased afterload (PE) may also have been related to $\alpha$-adrenergic coronary vasoconstriction. However, we believe this effect to be minimal, since potential $\alpha$-mediated vasoconstriction is likely overruled by metabolic demand [3, 18] and coronary flow velocity has been shown not to change during $\alpha$-adrenergic blockade with phentolamine or urapidil compared to phenylephrine alone [21, 34].

Confounding factors such as co-morbidities, medication, or microvascular disease can affect autoregulation $[5,12,22]$. Our study group is too small to allow a methodological comparison between subgroups. Moreover, in our study, each stenosis served as its own control. Therefore, we do not expect these factors to alter the general message of our study.

We did not measure absolute flow, but flow velocity, since this is the clinically available signal for intracoronary measurements. Consequently, we derived velocity-based resistance indices. In contrast to volume flow, flow velocity is much less dependent on perfusion territory, since it is preserved from proximal to distal segments in normal coronary arteries [28]. Sensor location was unchanged throughout the protocol steps for each patient. Nitroglycerine was given at the start of the protocol to minimize variations in vessel diameter due to changes in vascular tone at the measurement site [33]. Therefore, since the effect of interventions was expressed in terms of intra-subject comparisons to the respective control value, we do not expect the individual size of perfusion areas to differentially affect control and intervention measures or, consequently, our overall findings.

Although the magnitude of hemodynamic provocations produced in this study is not likely to be encountered during regular catheterization procedures, they demonstrate the potential for intrinsic biological variability in resting coronary flow to affect baseline stenosis indices.

\section{Conclusion}

Systemic hemodynamic perturbations caused resting flow velocity and BMR to adapt to altered myocardial metabolic demand. Consequently, basal indices of stenosis severity 
were affected, resulting in diagnostic re-classification according to $\mathrm{Pd} / \mathrm{Pa}$ and $\mathrm{BSR}$ thresholds. The results of future investigations should, therefore, be examined with attention to determinants of myocardial oxygen demand when assessing baseline indices of stenosis severity.

\section{Compliance with ethical standards}

Ethical standards The study protocol was approved by the institutional review and ethics committee (Ref: MEC 00/222). All patients gave written informed consent prior to their inclusion in the study.

Conflict of interest There was no industry involvement in any aspect of this study. MS received institutional research support from the University of Texas Health Science Center at Houston (for DEFINEFLOW, NCT02328820). JJP has served as speaker at educational events organized by St Jude Medical, Boston Scientific, and/or Philips-Volcano, manufacturers of sensor-equipped guidewires. The other authors report no conflicts of interest.

Financial support This work was supported by a Grant from the Dutch Heart Foundation (Hartstichting) (2000.090).

Open Access This article is distributed under the terms of the Creative Commons Attribution 4.0 International License (http://crea tivecommons.org/licenses/by/4.0/), which permits unrestricted use, distribution, and reproduction in any medium, provided you give appropriate credit to the original author(s) and the source, provide a link to the Creative Commons license, and indicate if changes were made.

\section{References}

1. Berry C, van 't Veer M, Witt N, Kala P, Bocek O, Pyxaras SA, McClure JD, Fearon WF, Barbato E, Tonino PA, De Bruyne B, Pijls NH, Oldroyd KG (2013) VERIFY (VERification of instantaneous wave-free ratio and fractional flow reserve for the assessment of coronary artery stenosis severity in EverydaY practice): a multicenter study in consecutive patients. J Am Coll Cardiol 61:1421-1427. doi:10.1016/j.jacc.2012.09.065

2. Bourdarias JP (1995) Coronary reserve: concept and physiological variations. Eur Heart J 16:2-6. doi:10.1093/eurheartj/16. suppl_I.2

3. Chilian WM (1991) Functional distribution of alpha 1- and alpha 2-adrenergic receptors in the coronary microcirculation. Circulation 84:2108-2122. doi:10.1161/01.CIR.84.5.2108

4. Cook CM, Ahmad Y, Shun-Shin MJ, Nijjer S, Petraco R, AlLamee R, Mayet J, Francis DP, Sen S, Davies JE (2016) Quantification of the effect of pressure wire drift on the diagnostic performance of fractional flow reserve, instantaneous wave-free ratio, and whole-cycle Pd/Pa. Circ Cardiovasc Interv 9:e002988. doi:10.1161/CIRCINTERVENTIONS.115.002988

5. Duncker DJ, Koller A, Merkus D, Canty JM Jr (2015) Regulation of coronary blood flow in health and ischemic heart disease. Prog Cardiovasc Dis 57:409-422. doi:10.1016/j.pcad. 2014.12.002

6. Echavarria-Pinto M, van de Hoef TP, van Lavieren MA, Nijjer S, Ibanez B, Pocock S, Quiros A, Davies J, Meuwissen M, Serruys PW, Macaya C, Piek JJ, Escaned J (2015) Combining baseline distal-to-aortic pressure ratio and fractional flow reserve in the assessment of coronary stenosis severity. JACC Cardiovasc Interv 8:1681-1691. doi:10.1016/j.jcin.2015.09.002
7. Escaned J, Echavarria-Pinto M, Garcia-Garcia HM, van de Hoef TP, de Vries T, Kaul P, Raveendran G, Altman JD, Kurz HI, Brechtken J, Tulli M, Von Birgelen C, Schneider JE, Khashaba AA, Jeremias A, Baucum J, Moreno R, Meuwissen M, Mishkel G, van Geuns RJ, Levite H, Lopez-Palop R, Mayhew M, Serruys PW, Samady H, Piek JJ, Lerman A, Group AIS (2015) Prospective assessment of the diagnostic accuracy of instantaneous wave-free ratio to assess coronary stenosis relevance: results of ADVISE II international, multicenter study (ADenosine Vasodilator Independent Stenosis Evaluation II). JACC Cardiovasc Interv 8:824-833. doi:10.1016/j.jcin.2015.01.029

8. Fukuda S, Shimada K, Maeda K, Kawasaki T, Kono Y, Miyahana R, Jissho S, Taguchi H, Yoshiyama M, Fujita M, Yoshikawa J (2012) Circadian variation in coronary flow velocity reserve and its relation to alpha1-sympathetic activity in humans. Int J Cardiol 157:216-220. doi:10.1016/j.ijcard.2010.12.052

9. Goodwill AG, Noblet JN, Sassoon D, Fu L, Kassab GS, Schepers L, Herring BP, Rottgen TS, Tune JD, Dick GM (2016) Critical contribution of KV1 channels to the regulation of coronary blood flow. Basic Res Cardiol 111:56. doi:10.1007/s00395-016-0575-0

10. Guarini G, Kiyooka T, Ohanyan V, Pung YF, Marzilli M, Chen YR, Chen CL, Kang PT, Hardwick JP, Kolz CL, Yin L, Wilson GL, Shokolenko I, Dobson JG Jr, Fenton R, Chilian WM (2016) Impaired coronary metabolic dilation in the metabolic syndrome is linked to mitochondrial dysfunction and mitochondrial DNA damage. Basic Res Cardiol 111:29. doi:10.1007/s00395-016$0547-4$

11. Hennigan B, Oldroyd KG, Berry C, Johnson N, McClure J, McCartney P, McEntegart MB, Eteiba H, Petrie MC, Rocchiccioli P, Good R, Lindsay MM, Hood S, Watkins S (2016) Discordance between resting and hyperemic indices of coronary stenosis severity: the VERIFY 2 study (a comparative study of resting coronary pressure gradient, instantaneous wave-free ratio and fractional flow reserve in an unselected population referred for invasive angiography). Circ Cardiovasc Interv 9:e004016. doi:10.1161/CIRCINTERVENTIONS.116.004016

12. Heusch G (2011) The paradox of alpha-adrenergic coronary vasoconstriction revisited. J Mol Cell Cardiol 51:16-23. doi:10. 1016/j.yjmcc.2011.03.007

13. Heusch G, Yoshimoto N, Muller-Ruchholtz ER (1982) Effects of heart rate on hemodynamic severity of coronary artery stenosis in the dog. Basic Res Cardiol 77:562-573. doi:10.1007/ BF01907947

14. Hoffman JI, Spaan JA (1990) Pressure-flow relations in coronary circulation. Physiol Rev 70:331-390

15. Jeremias A, Maehara A, Genereux P, Asrress KN, Berry C, De Bruyne B, Davies JE, Escaned J, Fearon WF, Gould KL, Johnson NP, Kirtane AJ, Koo BK, Marques KM, Nijjer S, Oldroyd KG, Petraco R, Piek JJ, Pijls NH, Redwood S, Siebes M, Spaan JA, van 't Veer M, Mintz GS, Stone GW (2014) Multicenter core laboratory comparison of the instantaneous wave-free ratio and resting $\mathrm{Pd} / \mathrm{Pa}$ with fractional flow reserve: the RESOLVE study. J Am Coll Cardiol 63:1253-1261. doi:10.1016/j.jacc.2013.09.060

16. Johnson NP, Jeremias A, Zimmermann FM, Adjedj J, Witt N, Hennigan B, Koo BK, Maehara A, Matsumura M, Barbato E, Esposito G, Trimarco B, Rioufol G, Park SJ, Yang HM, Baptista SB, Chrysant GS, Leone AM, Berry C, De Bruyne B, Gould KL, Kirkeeide RL, Oldroyd KG, Pijls NH, Fearon WF (2016) Continuum of vasodilator stress from rest to contrast medium to adenosine hyperemia for fractional flow reserve assessment. JACC Cardiovasc Interv 9:757-767. doi:10.1016/j.jcin.2015.12. 273

17. Johnson NP, Kirkeeide RL, Asrress KN, Fearon WF, Lockie T, Marques KM, Pyxaras SA, Rolandi MC, van 't Veer M, De Bruyne B, Piek JJ, Pijls NH, Redwood S, Siebes M, Spaan JA, Gould KL (2013) Does the instantaneous wave-free ratio 
approximate the fractional flow reserve? J Am Coll Cardiol 61:1428-1435. doi:10.1016/j.jacc.2012.09.064

18. Jones CJ, Kuo L, Davis MJ, Chilian WM (1993) Myogenic and flow-dependent control mechanisms in the coronary microcirculation. Basic Res Cardiol 88:2-10. doi:10.1007/BF00788525

19. Kanatsuka H, Lamping KG, Eastham CL, Dellsperger KC, Marcus ML (1989) Comparison of the effects of increased myocardial oxygen consumption and adenosine on the coronary microvascular resistance. Circ Res 65:1296-1305. doi:10.1161/ 01.RES.65.5.1296

20. Kern MJ (2012) Basal stenosis resistance: another adenosine-free contender for the lesion assessment crown? Circ Cardiovasc Interv 5:456-458. doi:10.1161/CIRCINTERVENTIONS.112. 972158

21. Kolyva C, Verhoeff BJ, Spaan JA, Piek JJ, Siebes M (2008) Increased diastolic time fraction as beneficial adjunct of alpha1adrenergic receptor blockade after percutaneous coronary intervention. Am J Physiol Heart Circ Physiol 295:H2054-H2060. doi:10.1152/ajpheart.91400.2007

22. Komaru T, Kanatsuka H, Shirato K (2000) Coronary microcirculation: physiology and pharmacology. Pharmacol Ther 86:217-261. doi:10.1016/S0163-7258(00)00057-7

23. Mamas MA, Horner S, Welch E, Ashworth A, Millington S, Fraser D, Fath-Ordoubadi F, Neyses L, El-Omar M (2010) Resting $\mathrm{Pd} / \mathrm{Pa}$ measured with intracoronary pressure wire strongly predicts fractional flow reserve. J Invasive Cardiol 22:260-265

24. McGinn AL, White CW, Wilson RF (1990) Interstudy variability of coronary flow reserve. Influence of heart rate, arterial pressure, and ventricular preload. Circulation 81:1319-1330. doi:10.1161/ 01.CIR.81.4.1319

25. Modi BN, Ellis H, Arri S, Lumley M, Briceno N, Williams R, Clapp B, Redwood S, Marber M, Perera D (2016) Baseline coronary flow varies with normal cardiac catheter laboratory stimuli. Heart 102:A10. doi:10.1136/heartjnl-2016-309588.18 (abstr)

26. Nijjer SS, de Waard GA, Sen S, van de Hoef TP, Petraco R, Echavarria-Pinto M, van Lavieren MA, Meuwissen M, Danad I, Knaapen P, Escaned J, Piek JJ, Davies JE, van Royen N (2016) Coronary pressure and flow relationships in humans: phasic analysis of normal and pathological vessels and the implications for stenosis assessment: a report from the Iberian-Dutch-English (IDEAL) collaborators. Eur Heart J 37:2069-2080. doi:10.1093/ eurheartj/ehv626

27. Nolte F, van de Hoef TP, de Klerk W, Baan J Jr, Lockie TP, Spaan JA, Piek JJ, Siebes M (2014) Functional coronary stenosis severity assessed from the mean pressure gradient-velocity relationship obtained by contrast medium-induced submaximal hyperaemia. EuroIntervention 10:320-328. doi:10.4244/ EIJV10I3A55

28. Ofili EO, Labovitz AJ, Kern MJ (1993) Coronary flow velocity dynamics in normal and diseased arteries. Am J Cardiol 71:3D9D. doi:10.1016/0002-9149(93)90128-Y

29. Page BJ, Young RF, Suzuki G, Fallavollita JA, Canty JM Jr (2013) The physiological significance of a coronary stenosis differentially affects contractility and mitochondrial function in viable chronically dysfunctional myocardium. Basic Res Cardiol 108:354. doi:10.1007/s00395-013-0354-0
30. Petraco R, Park JJ, Sen S, Nijjer SS, Malik IS, Echavarria-Pinto M, Asrress KN, Nam CW, Macias E, Foale RA, Sethi A, Mikhail GW, Kaprielian R, Baker CS, Lefroy D, Bellamy M, Al-Bustami M, Khan MA, Gonzalo N, Hughes AD, Francis DP, Mayet J, Di Mario C, Redwood S, Escaned J, Koo BK, Davies JE (2013) Hybrid iFR-FFR decision-making strategy: implications for enhancing universal adoption of physiology-guided coronary revascularisation. EuroIntervention 8:1157-1165. doi:10.4244/ EIJV8I10A179

31. Pijls NH, van Nunen LX (2015) Fractional flow reserve, maximum hyperemia, adenosine, and regadenoson. Cardiovasc Revasc Med 16:263-265. doi:10.1016/j.carrev.2015.06.003

32. Robertson KE, Hennigan B, Berry C, Oldroyd KG (2015) Physiological assessment of coronary lesion severity: fractional flow reserve versus nonhyperaemic indices. Coron Artery Dis 26(Suppl 1):e8-e14. doi:10.1097/MCA.0000000000000212

33. Rolandi MC, De Silva K, Lumley M, Lockie TP, Clapp B, Spaan JA, Perera D, Siebes M (2014) Wave speed in human coronary arteries is not influenced by microvascular vasodilation: implications for wave intensity analysis. Basic Res Cardiol 109:405. doi:10.1007/s00395-014-0405-1

34. Rossen JD, Winniford MD (1993) Effect of increases in heart rate and arterial pressure on coronary flow reserve in humans. J Am Coll Cardiol 21:343-348. doi:10.1016/0735-1097(93)90673-O

35. Sen S, Escaned J, Malik IS, Mikhail GW, Foale RA, Mila R, Tarkin J, Petraco R, Broyd C, Jabbour R, Sethi A, Baker CS, Bellamy M, Al-Bustami M, Hackett D, Khan M, Lefroy D, Parker KH, Hughes AD, Francis DP, Di Mario C, Mayet J, Davies JE (2012) Development and validation of a new adenosine-independent index of stenosis severity from coronary waveintensity analysis: results of the ADVISE (ADenosine Vasodilator Independent Stenosis Evaluation) study. J Am Coll Cardiol 59:1392-1402. doi:10.1016/j.jacc.2011.11.003

36. Siebes M, Verhoeff BJ, Meuwissen M, de Winter RJ, Spaan JA, Piek JJ (2004) Single-wire pressure and flow velocity measurement to quantify coronary stenosis hemodynamics and effects of percutaneous interventions. Circulation 109:756-762. doi:10. 1161/01.CIR.0000112571.06979.B2

37. van de Hoef TP, Petraco R, van Lavieren MA, Nijjer S, Nolte F, Sen S, Echavarria-Pinto M, Henriques JP, Koch KT, Baan J Jr, de Winter RJ, Siebes M, Spaan JA, Tijssen JG, Meuwissen M, Escaned J, Davies JE, Piek JJ (2016) Basal stenosis resistance index derived from simultaneous pressure and flow velocity measurements. EuroIntervention 12:e199-e207. doi:10.4244/ EIJV12I2A33

38. van Lavieren MA, Piek JJ (2016) Resting indices of coronary lesion severity: not always as simple as it seems. Circ Cardiovasc Interv 9:e003747. doi:10.1161/CIRCINTERVENTIONS.116. 003747

39. Vargas Pelaez AF, Gao Z, Ahmad TA, Leuenberger UA, Proctor DN, Maman SR, Muller MD (2016) Effect of adrenergic agonists on coronary blood flow: a laboratory study in healthy volunteers. Physiol Rep 4:e12806. doi:10.14814/phy2.12806

40. Verdier-Watts F, Rioufol G, Mewton N, Sanchez I, Green L, Bonnefoy-Cudraz E, Finet G (2015) Influence of arterial hypotension on fractional flow reserve measurements. EuroIntervention 11:416-420. doi:10.4244/EIJV11I4A82 